\title{
Article \\ Grain Rotation Accommodated GBS Mechanism for the Ti-6Al-4V Alloy during Superplastic Deformation
}

\author{
Junzhou Yang (1) and Jianjun $\mathrm{Wu}^{*}$ \\ School of Mechanical Engineering, Northwestern Polytechnical University, Xi'an 710072, China; \\ yjz@mail.nwpu.edu.cn \\ * Correspondence: wujj@nwpu.edu.cn; Tel.: +86-029-8849-3101
}

Citation: Yang, J.; Wu, J. Grain Rotation Accommodated GBS Mechanism for the Ti-6Al-4V Alloy during Superplastic Deformation. Crystals 2021, 11, 991. https:// doi.org/10.3390/cryst11080991

Academic Editors: Antonio J. Gámez, Luis García Barrachina, Vit Janik, Donato Sorgente and Vincent Velay

Received: 26 July 2021

Accepted: 18 August 2021

Published: 20 August 2021

Publisher's Note: MDPI stays neutral with regard to jurisdictional claims in published maps and institutional affiliations.

Copyright: (c) 2021 by the authors. Licensee MDPI, Basel, Switzerland. This article is an open access article distributed under the terms and conditions of the Creative Commons Attribution (CC BY) license (https:// creativecommons.org/licenses/by/ $4.0 /)$.

\begin{abstract}
An investigation of flow behavior and the deformation mechanism for Ti-6Al-4V alloy during the superplastic deformation process is presented in this paper. Constant strain rate tensile tests were performed at $890-950^{\circ} \mathrm{C}$ and strain rates of $10^{-2}, 10^{-3}$, and $10^{-4} / \mathrm{s}$. Then, surface observation by Optical Microscope (OM), Scanning Electron Microscopy (SEM), and Electron Backscattered Diffraction (EBSD) was applied to obtain the microstructure mechanism. With pole figure maps (PF) for $\alpha$-phase, obvious texture gradually changed in the main deformation direction. For the titanium alloy, the evolution of texture in deformed samples was attributed to grain rotation (GR). Significant grain rearrangement occurred between grains after deformation. A complete grain rotation accommodated grain boundary sliding (GBS) deformation mechanism is proposed, which can explain texture evolution without grain deformation.
\end{abstract}

Keywords: superplasticity; Ti-6Al-4V; grain rotation; deformation mechanism

\section{Introduction}

The Ti-6Al-4V alloy, as an $\alpha / \beta$ titanium, has many mechanical properties, such as low density, high specific strength, and excellent corrosion resistance, which have been widely exploited in aerospace industries [1,2]. For the manufacture of parts with complex shapes, superplastic forming (SPF) is always applied due to large deformation resistance at room temperature $[3,4]$. Superplasticity refers to the property of materials that achieve great elongation without fracture. With more than 80 years of research, superplasticity has been reported in many metallic system alloys based upon aluminum, magnesium, zinc, and steel [5,6]. Great ductility can also be obtained in some ceramics and geological materials [7]. Although some attempts have been tried to optimize the SPF process windows by changing the metallography structures of materials [8-11], the current mainstream view still holds that the superplasticity of metals needs two compulsory requirements: a high temperatures and certain strain rate regions [5]. For the Ti-6Al-4V alloy, the elevated temperatures are at about $900{ }^{\circ} \mathrm{C}$ and the controlled strain rates need to be within the range of $10^{-4}$ to $10^{-2} / \mathrm{s}$.

The superplasticity of materials has been the focus of an abundance of papers [12-14]. A body-centered cubic structure (BBC) for the $\beta$ phase has more slip systems than a hexagonal close-packed structure (HCP) for the $\alpha$ phase, so the larger the $\beta$ fraction, the easier it is to deform. However, the $\beta$ phase is a structure that grows easily at high temperatures, which is incompatible with the demand for fine equiaxial grain size. Thus, a clear deformation mechanism of alloys in SPF is needed. Besides, the flow behavior can be divided into three deformation regions: (i) a diffusion creep mechanism under low strain rate (I region; (ii) grain boundary sliding (GBS) under medium strain rate (II region, i.e., superplastic forming region) and (iii) a dislocation creep mechanism under high strain rate (III region). Even in the deformations dominated by the diffusion creep mechanism, grain boundary sliding still can contribute 50 to $70 \%$ in the II region [15]. Thus, the GBS playing a dominant role in SPF has been extensively recognized [16,17]. 
In recent years, more attention has been paid to the microstructural evolution and deformation mechanism of superplastic deformation. Mosleh et al. $[18,19]$ investigated the superplasticity of Ti-6Al-4V and Ti-4Al-1V-3Mo alloys, revealing that samples with larger recrystallized fractions showed better superplasticity and higher quality of the formed parts with a more uniform thickness distribution in cross-section. The effects of microstructure evolutions on the forming process were also discussed by Wang et al. [20]. Dynamic recrystallization (DRX) occurs during tensile deformation and can refine the microstructure, thus, the thickness uniformity of the formed part can be improved by increasing the feed length. Besides, Wu et al. [21] investigated the microscopic nature of the anisotropy of TA32 and proposed that the thermal effect and DRX-induced grain refinement lead to a decrease and increase in r-value, respectively. It can be seen that the influence of microstructure mechanisms on the material remains a focus of superplasticity research.

The most controversially debated issue concerns the accommodation mechanism of GBS during superplastic deformation. Ashby and Verrall [22] first proposed the diffusionaccommodated GBS mechanism. The unit cells were constituted by four grains, and the movement could produce the 0.55 true strain with the same grain shapes. This mechanism has four irreversible processes: diffusion, interfacial reaction, GBS, and fluctuation of the boundary area. For a two-phase alloy, further discussion on the Ashby-Verrall model considered that the phase boundaries between different phases are generally curved, for which the speed atoms at boundaries in each phase are inconsistent [23,24]. Ball and Huchison [25] provided a model in which the accommodated mechanism is dislocation motion, which uses a group of grains as a unit slip until the unfavorably oriented grains hindered their motions. Another modified model of adjoint dislocation coordination was proposed by Weinstein et al. [26], in which the grains no longer slip as a unit of a combined unit, but a unit consists of only one single grain. Dislocations occur at grain boundary ridges and protrusions, pass through grains, and are blocked at grain boundary slugs. Paidar et al. [27] proposed a grain translocation model for the idea of grain rotation, dividing grain boundaries into a pressurized grain interface, a pulled grain interface, and a slip interface. The grain boundary dislocation moves at the sliding interface and climbs at the compression and tension interface. For the Ti-6Al-4V alloy during the SPF, whether there is a certain accommodation mechanism or a combination of several mechanisms for GBS is still debatable.

With the above in mind, the purpose of this research was to investigate the deformation mechanism for Ti-6Al-4V alloy during the superplastic deformation process. The flow behavior was first explored, then a series of surface observations for samples cut from the specimens before and after testing was performed. Finally, the results of these experiments were explored for the deformation mechanism.

\section{Materials and Methods}

The Ti-6Al-4V alloy under investigation in this paper was a titanium sheet with a thickness of $1 \mathrm{~mm}$. The weight percentage obtained by Energy Dispersive Spectrometry (EDS) was listed as: $88.31 \% \mathrm{Ti}, 5.59 \% \mathrm{Al}, 4.85 \% \mathrm{~V}$, and $1.25 \% \mathrm{C}$. This observation was performed on the ZEISS SUPRA Microscopy at the Shaanxi Material Analysis and Research Center, China. In addition, other microcosmic experiments involved in this paper are also carried out by this institution.

\subsection{High-Temperature Tensile Testing}

The specimens for the constant strain rate high-temperature tensile tests were cut from the received material by a Wire Cut Electrical Discharge Machining (WEDM), the dimensions of which are shown in Figure 1. Constant strain rate tensile tests were performed on a Shimazu Electronic Universal Testing Machine according to the GB/T 4338-2006. The heating furnace in the testing machines had three heating zones, and the temperature of each heat zone was measured by an independent thermocouple. The samples were heated to a set temperature at $5{ }^{\circ} \mathrm{C} / \mathrm{s}$. The specimens were held for $15 \mathrm{~min}$ after the test 
temperatures were reached to ensure uniform temperatures and microstructures. To ensure good contact between the specimens and the thermocouples, the specimens weremanually sanded with 1000 \# sandpaper before the tensile tests. The selected temperatures during the experiments were $890^{\circ} \mathrm{C}, 920^{\circ} \mathrm{C}$ and $950{ }^{\circ} \mathrm{C}$, and strain rates were set at $10^{-2}, 10^{-3}$ and $10^{-4} / \mathrm{s}$, which are the traditional process windows for Ti-6Al-4V superplastic forming $[5,28]$. The specimens were continuously stretched until any of the following conditions were met: (i) specimens rupturing; (ii) maximum elongation due to the geometrical dimensions of furnace chamber; (iii) maximum testing time for the machine to withstand high temperature. Assuming that no volume changed occurred during the deformation, the true stress, and true strain can be obtained by the following expression:

$$
\left\{\begin{array}{c}
\sigma=\mathrm{FL} /\left(\mathrm{A}_{0} \mathrm{~L}_{0}\right) \\
\varepsilon=\ln \left(\mathrm{L} / \mathrm{L}_{0}\right)
\end{array}\right.
$$

where $\sigma$ is the true stress, $\varepsilon$ is the true strain, $\mathrm{F}$ is the load applied to the crossheads, $\mathrm{A}_{0}$ is the initial cross-sectional area of the specimen, $\mathrm{L}_{0}$ is the initial gauge of the specimen, and $\mathrm{L}$ is the gauge of the specimen. To study the deformation mechanism, tensile tests with strains of $0.2,0.5$, and 0.8 were added to each temperature and strain rate for subsequent microscopic observations. Due to high consumption of the high-temperature tensile test process and the fact that tests at different strains were already available for verification, all tensile tests under the same conditions were carried out only once.

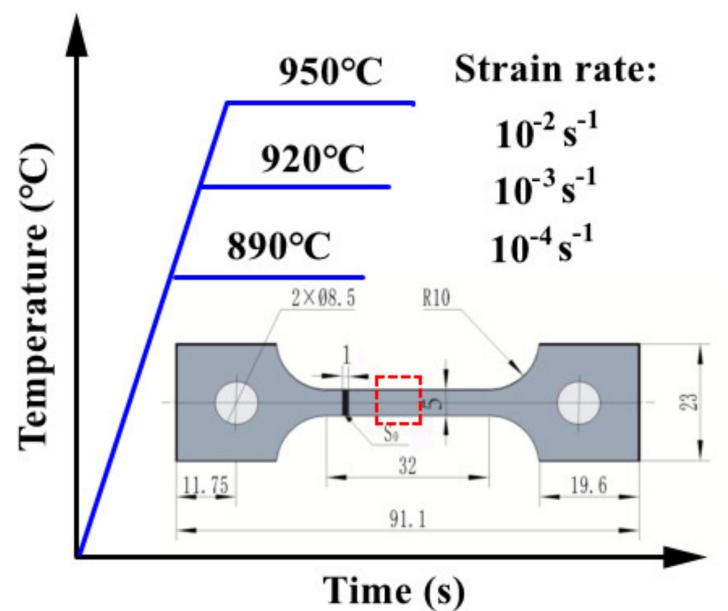

Figure 1. The dimensions of the tensile test specimen.

\subsection{Microstructural Characterization}

The microstructural changes of the specimens before and after high-temperature tensile testing were observed by surface observation using Electron Back-scattered Diffraction (EBSD), Scanning Electron Microscopy (SEM), and Optical Microscopy (OM). All specimens for metallographic testing were cut from the deformation zones of the tensile specimens (marked with a red dotted box in Figure 1). EBSD tests were used to identify grain orientation evolution during deformation. Before metallurgical observation, all the samples were hand-polished with 500, 1000, and 3000 \# sandpaper, then the electro dissection experiments were carried out using a Struers Lectropol-5, which was operated at $20{ }^{\circ} \mathrm{C}, 22 \mathrm{~V}$ for the $40 \mathrm{~s}$. The electrolyte for Ti-6Al-4V alloy consisted of $\mathrm{HClO}_{4}: \mathrm{CH}_{3} \mathrm{OH}: \mathrm{CH}_{3}\left(\mathrm{CH}_{2}\right)_{3} \mathrm{O}=3: 32: 15$. Measurements were made using an SU3500 scanning electron microscope equipped with an Oxford energy spectrum and EBSD camera, and the experimental data were analyzed by Channel 5 software. In addition, SEM samples combined with the OM results were applied to confirm the deformation mechanism of the Ti-6Al-4V alloy. 


\section{Results and Discussion}

As observed by optical microscopy (OM), the received alloy consisted of a large number of equiaxed $\alpha$-phases and interspersed $\beta$-phases at room temperature, as shown in Figure 2.



Figure 2. The initial microstructure of the received specimens.

\subsection{Mechanical Behavior}

Figure 3 shows the results of the specimens after high-temperature tensile tests. Generally speaking, the flow behavior had the following characteristics:

(i) In the beginning stage of the deformation, significant strain hardening occurred, which resulted from massive dislocations multiplied in the material. After a certain value of strain was exceeded, the flow stresses showed varying degrees of strain softening. This was because cross-slip of dislocations were the dominant softening mechanism in the initial stages of plastic deformation, but this dynamic strain softening was not sufficient to compensate for the hardening caused by the increased dislocation densities.

(ii) For deformation at high strain rates $\left(10^{-3}-10^{-2} / \mathrm{s}\right)$, continuous stress was seen in the curves. However, when the material deformed at a strain rate of $10^{-4} / \mathrm{s}$, only strain hardening was observed. The essence of this steady-state flow stress was a balance between strain hardening due to dislocation multiplication, and softening due to dislocation rearrangement with mutual destruction of dissimilar dislocations.

For the Ti-6Al-4V alloy at elevated temperatures, flow behavior was sensitive to strain rates. The higher the strain rate, the larger the flow stress. This is due to the fact that as the deformation rate increased, the strain per unit time increased, producing a greater concentration of dislocation density. In addition, for deformations with high strain rates, dislocations moved faster and the offset of different dislocations increased. However, the concentration of equilibrium dislocations increased throughout the process and this led to an increase in the deformation resistance of the material during deformation. The strain rate sensitivity factor $(\mathrm{m})$ can be determined by taking the slope of the logarithmic coordinate curve of stress $\sigma$ and strain rate $\dot{\varepsilon}$, i.e., $\mathrm{m}=\mathrm{d} \ln \sigma / \mathrm{d} \ln \dot{\varepsilon}$. The maps of strain rate sensitivity factors during the strain ranges from $0.2-0.7$ are given in Figure 4 . The strain rate sensitivity factors showed a significant dependence on strain rates and temperatures. For the materials in this study, $\mathrm{m}$ reached maximum values at $890{ }^{\circ} \mathrm{C}$ with a strain rate of $10^{-2} / \mathrm{s}$, and decreased with both increasing temperature and decreasing strain rate. In addition, the maximum strain rate sensitivity factor increased with the larger degree of deformation, due to dynamic recrystallization in titanium and smaller grains occurring during the deformation process. 

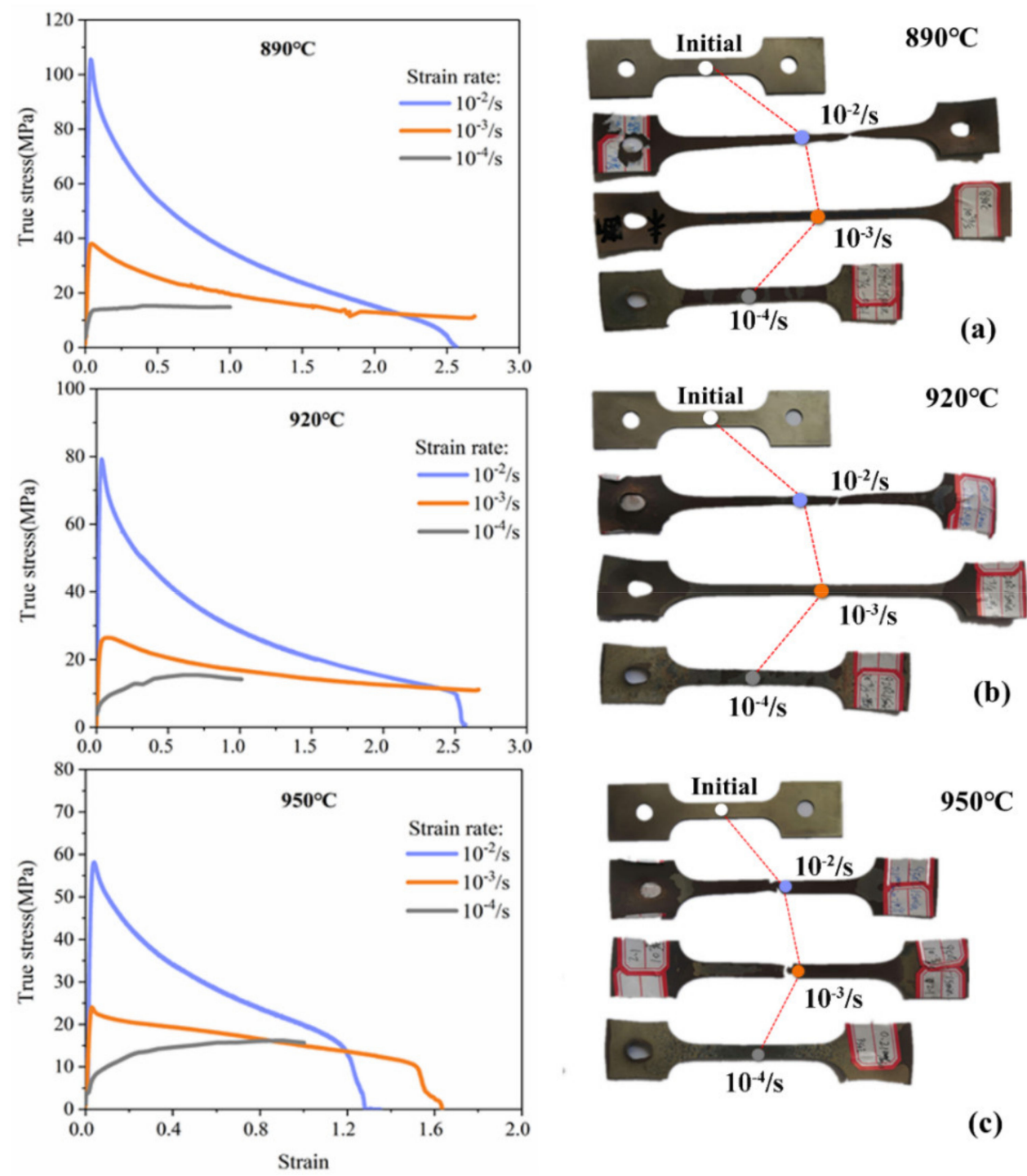

(c)

Figure 3. Specimens and flow stresses before and after testing: (a) $890^{\circ} \mathrm{C}$; (b) $920{ }^{\circ} \mathrm{C}$; (c) $950{ }^{\circ} \mathrm{C}$.

\subsection{Microstructure Observations}

To investigate underlying deformation mechanisms, SEM observations were made for each metallographic test sample. The results at $890^{\circ} \mathrm{C}, 10^{-3} / \mathrm{s}$ and $920^{\circ} \mathrm{C}, 10^{-4} / \mathrm{s}$ at the strain of $0.2,0.5$, and 0.8 are given in Figure 5. In Figure 5a,b, the microstructures still retain initial equiaxed grains at $\varepsilon=0.2$, indicating that the dominant titanium alloy deformation mechanism is GBS. This agrees with reports in the literature [29], and it is currently the consensus that maintaining grain shape is essential for continuous deformation.

Figure $5 c$ shows the SEM observation results when the strains reach 0.5 at $890{ }^{\circ} \mathrm{C}$, $10^{-3} / \mathrm{s}$. Fine grains a-g are observed, indicating that significant DRX has occurred. The process of DRX can be controlled by stacking fault energy and grain sizes, and the initial microstructures and forming process also contribute. According to the Hell-Petch formula [30]

$$
\tau=\mathrm{kd}^{-1 / 2}
$$

where $\tau$ is thermal stress related to the grain size, $\mathrm{d}$ is the grain size, and $\mathrm{k}$ is the material constant. Grain sizes change to small values, then a decrease in the tensile strength and an increase in ductility of the material may be a priority. 

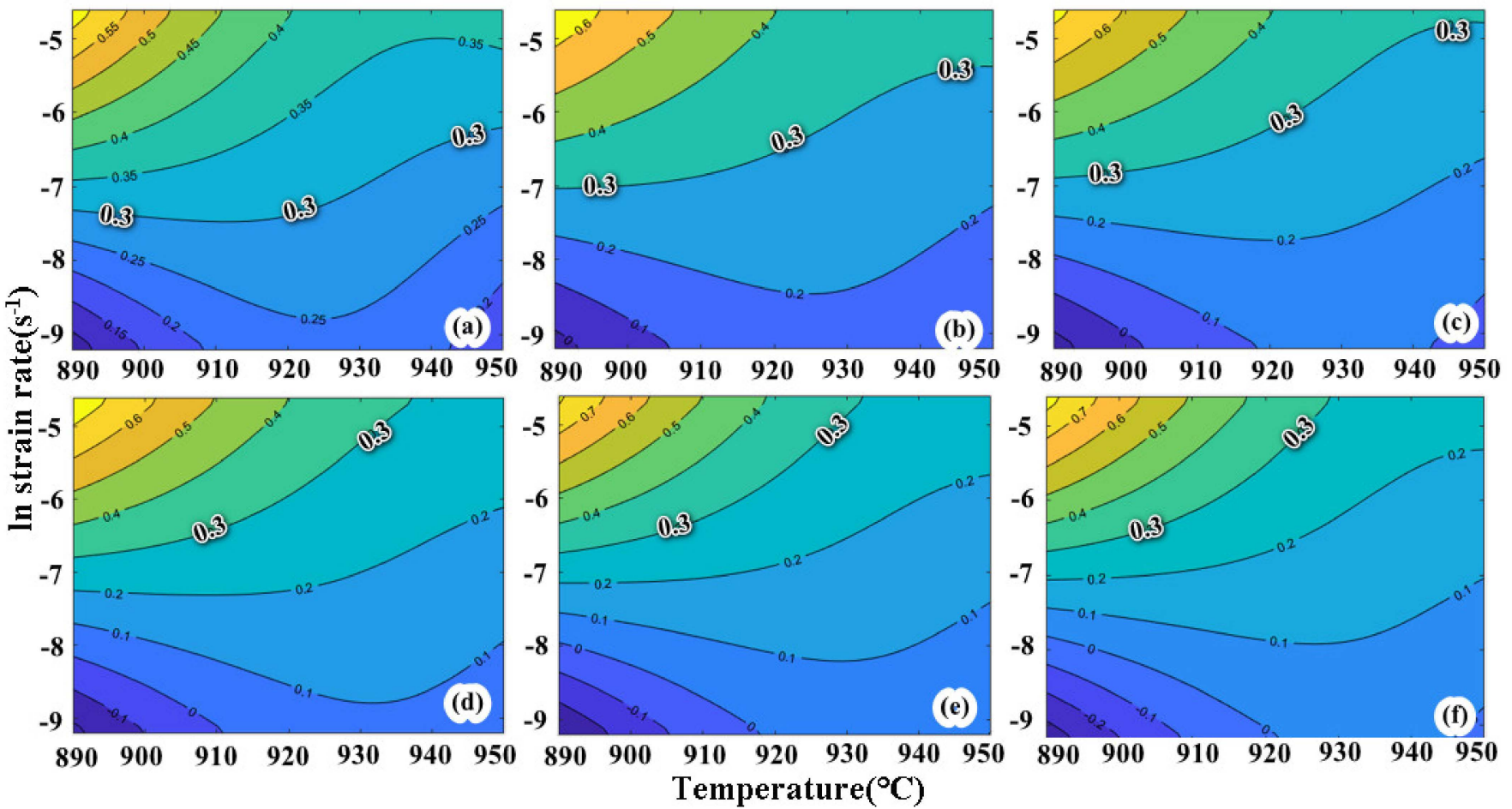

Figure 4. Maps of the strain rate sensitivity factor at different strains: $(\mathbf{a}) \varepsilon=0.2,(\mathbf{b}) \varepsilon=0.3,(\mathbf{c}) \varepsilon=0.4,(\mathbf{d}) \varepsilon=0.5,(\mathbf{e}) \varepsilon=0.6$, and $(\mathbf{f}) \varepsilon=0.7$.
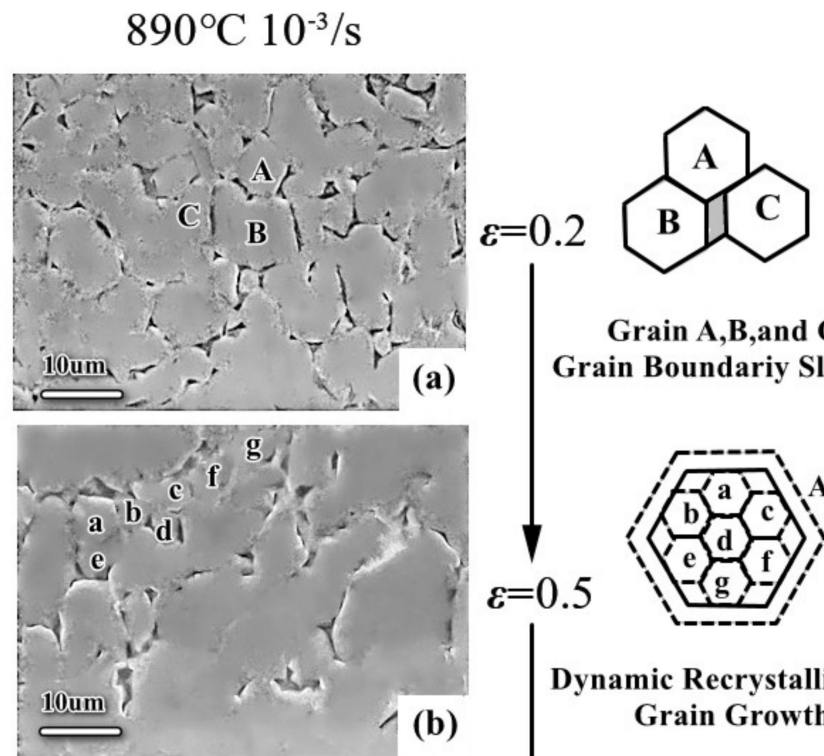

Grain A,B, and C Grain Boundariy Sliding
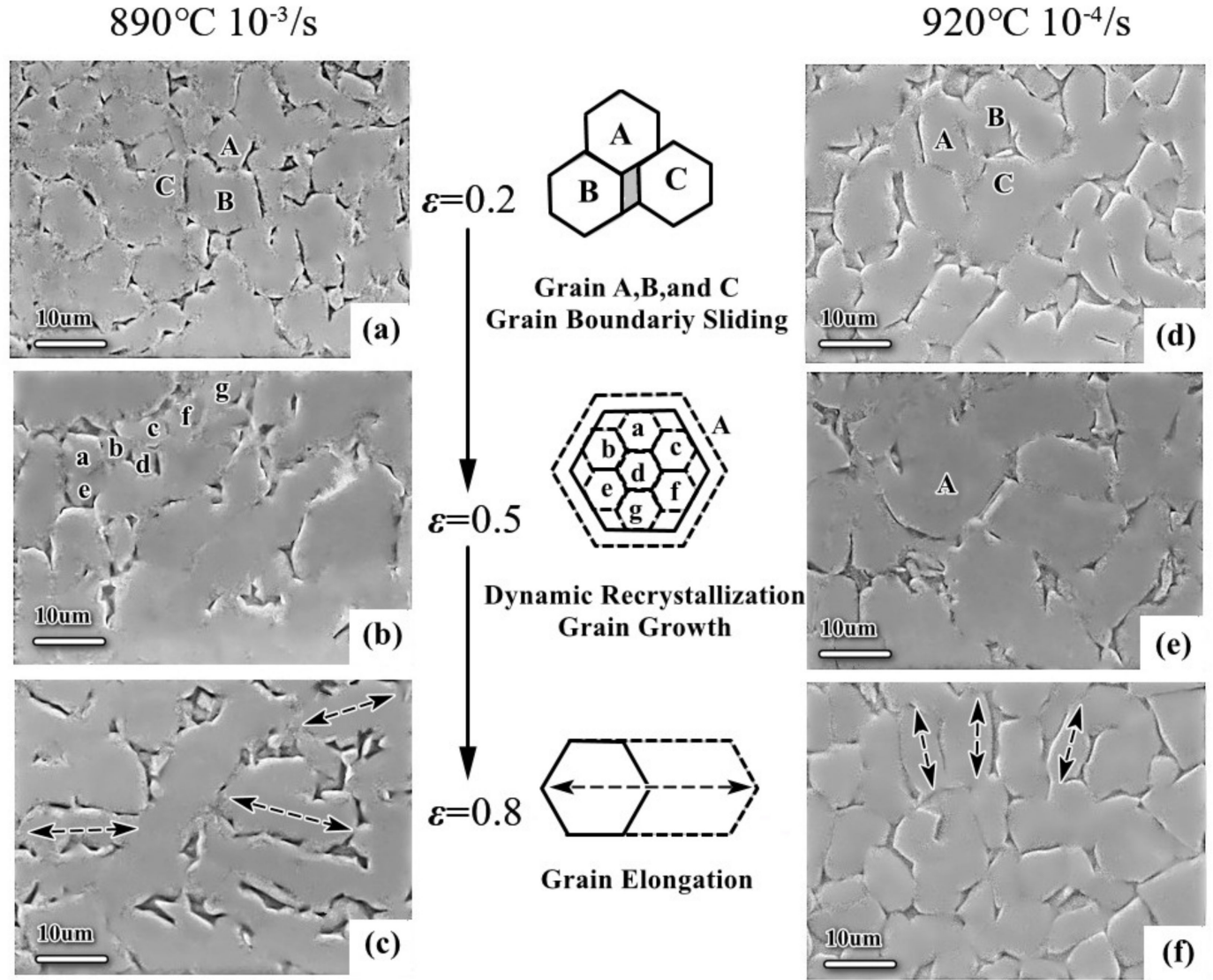

Figure 5. SEM observations for the Ti-6Al-4V alloy. (a) $890^{\circ} \mathrm{C}, 10^{-3} / \mathrm{s}, \varepsilon=0.2 ;$ (b) $890^{\circ} \mathrm{C}, 10^{-3} / \mathrm{s}, \varepsilon=0.5 ;(\mathbf{c}) 890^{\circ} \mathrm{C}, 10^{-3} / \mathrm{s}$, $\varepsilon=0.8 ;(\mathbf{d}) 920^{\circ} \mathrm{C}, 10^{-4} / \mathrm{s}, \varepsilon=0.2 ;(\mathbf{e}) 920^{\circ} \mathrm{C}, 10^{-4} / \mathrm{s}, \varepsilon=0.5 ;(\mathbf{f}) 920^{\circ} \mathrm{C}, 10^{-4} / \mathrm{s}, \varepsilon=0.8$. 
The evolution of grain sizes is shown in Figure 6, and were obtained by EBSD observations. The scatter points are the experimental data and the dashed lines are the results of the linear fit of these scatter points representing the trends of grain sizes. For the deformation at $890^{\circ} \mathrm{C}$ and $10^{-2} / \mathrm{s}$, DRX was significantly observed. For the Ti-6Al$4 \mathrm{~V}$ alloy, most research has discussed microstructure evolution based on the nucleation and growth of recrystallized grains, with the recrystallized grains scattered around the grain boundaries, i.e., discontinuous dynamic recrystallization (DDRX). However, similar distribution features were not observed in our SEM results, so continuous dynamic recrystallization (CDRX) should be the DRX modus for the Ti-6Al-4V alloy. The CDRX process focuses on the transformation of high-angle grain boundaries (HAGBs) and low-angle grain boundaries (LAGBs). Commonly, $15^{\circ}$ is used to distinguish the HAGBs and LAGBs. Fine grains can be generated as the misorientations of the LAGBs reach critical values. Two main mechanisms for the evolution of LAGBs occur: (i) the sub-grain boundaries prevent the dislocation motions and accumulate the dislocation densities, which increases the misorientation of the LAGBs that then turn into HAGBs; (ii) the subgrains are surrounded by subgrain boundaries or grain boundaries. As the deformation progresses, grain rotation occurs between the subgrains with different orientation differences, and then the LAGBs are converted into HABs.
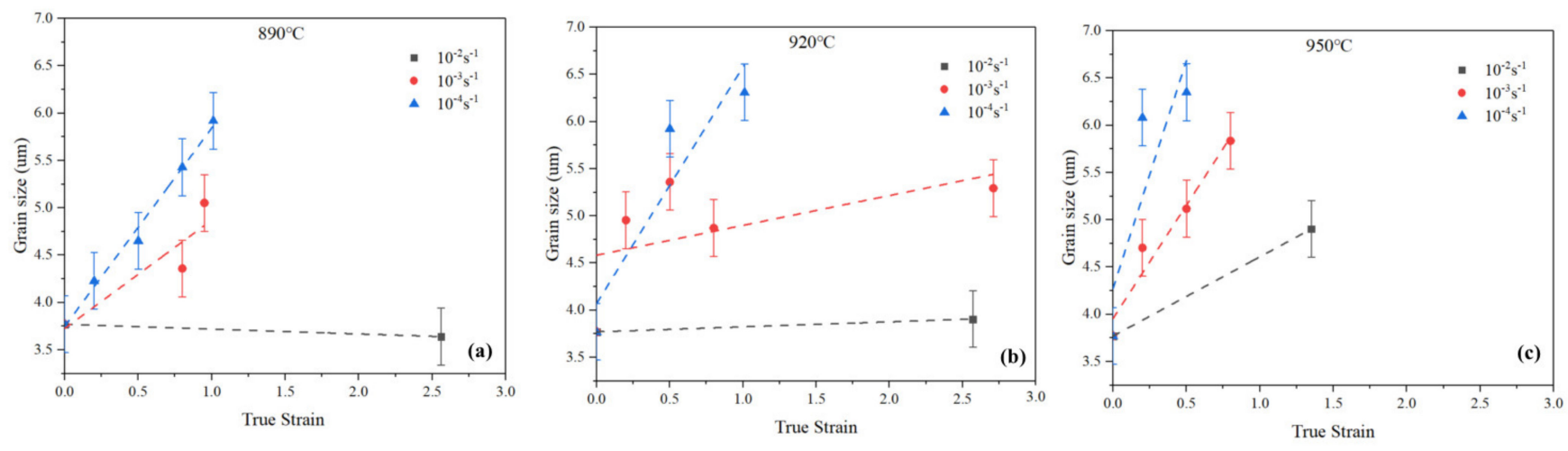

Figure 6. Grain sizes measured by EBSD observation. (a) $890^{\circ} \mathrm{C}$, (b) $920^{\circ} \mathrm{C}$, and (c) $950{ }^{\circ} \mathrm{C}$.

For the deformation at $920^{\circ} \mathrm{C}$ with a strain rate of $10^{-4} / \mathrm{s}$, the grain growth is visible in Figures $5 \mathrm{~d}$ and $6 \mathrm{~b}$. With an increase in temperature, the $\alpha$-phase of Ti-6Al-4V alloy transforms into the $\beta$-phase, which may cause a decrease in grain size for the equiaxed $\alpha$-phase. This is different from the test results. One reason for this is that when the temperature rises to $920^{\circ} \mathrm{C}$, the phase boundary diffusion of the $\alpha$-phase increases, allowing it to swallow up small grains and contribute to grain growth. Another reason is that when deforming at a low strain rate of $10^{-4} / \mathrm{s}$, dissimilar dislocations can be sufficiently offset from each other, so the CDRX is weakened with low dislocation densities and the grains become larger.

Conversely, as in Figure $5 \mathrm{e}, \mathrm{f}$ at $\varepsilon=0.8$, it is difficult for the grains to remain equiaxed and grain elongation occurs in the direction of stretching. As can be seen in Figure $3 a, b$, the specimens did not fracture at this condition, which means that the grain elongation did not cause significant GBS discontinuities. This phenomenon may occur because (i) finer equiaxed grains may still occur after the current stage of grain elongation, being an intermediate transition of CDRX, and (ii) most of the grains are still equiaxed, so the roles played by these grains are not dominant.

\subsection{Grain Rotation}

Figure 7 illustrates the texture evolution of the HCP crystal structure by pole figures before and after testing. The texture intensities are characterized by multiples of the uniform density (MUD). The initial maximum MUD of received material was 6.60, and the values increased for all temperature and strain rates except for $890^{\circ} \mathrm{C}$ with $10^{-3} / \mathrm{s}$ and 
$920^{\circ} \mathrm{C}$ with $10^{-2} / \mathrm{s}$. The Ti-6Al-4V alloy titanium has an obvious texture, and the basal texture is dominant in Figure 7a. As shown in Figure $7 \mathrm{~b}-\mathrm{j}$, the evolution of texture in deformed samples can be attributed to the grain rotation (GR). GR has been reported in the literature [31], and whether the grains rotate or not mainly depends on the relative movement between the grain and surrounding grains. During superplastic deformation, GR does not contribute to the total strain but can provide degrees of freedom for the deformation. Grain rotation is an accommodated mechanism of GBS, and the two mechanisms together reduce the total texture. Then, further deformations produce new textures, the cycle repeats and continued deformations are obtained.

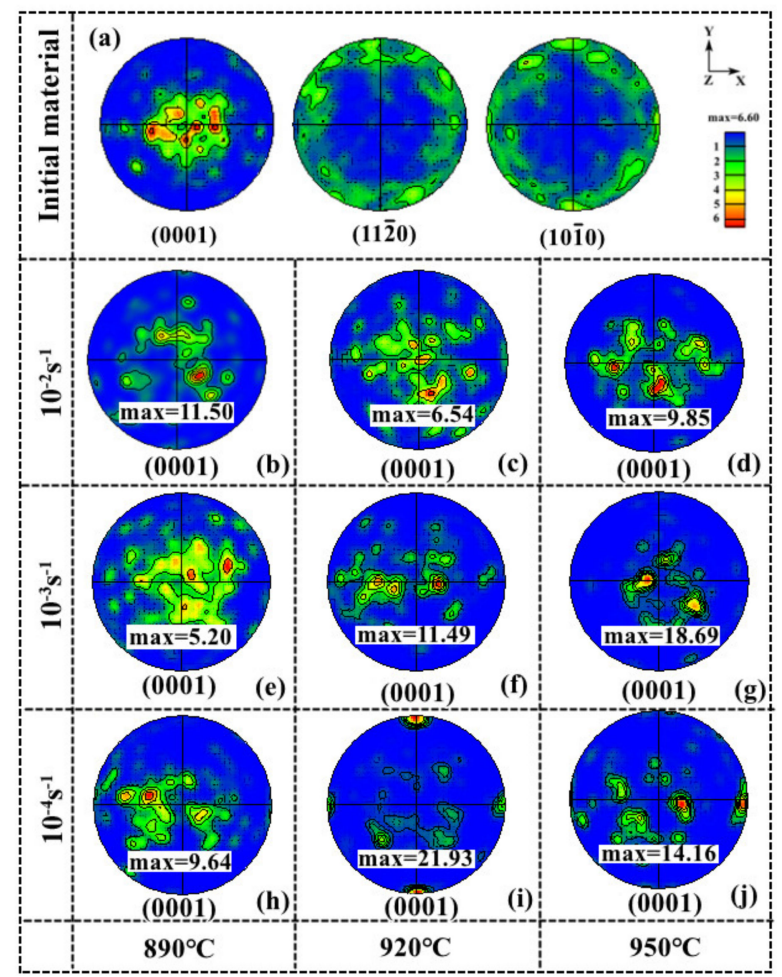

Figure 7. EBSD analysis of pole figure maps (PF) for $\alpha$-phase for the Ti-6Al-4V alloy. (a) Initial material; (b) $890^{\circ} \mathrm{C}, 10^{-2} / \mathrm{s}$; (c) $890^{\circ} \mathrm{C}, 10^{-3} / \mathrm{s}$; (d) $890^{\circ} \mathrm{C}, 10^{-4} / \mathrm{s}$; (e) $920^{\circ} \mathrm{C}, 10^{-2} / \mathrm{s}$; (f) $920^{\circ} \mathrm{C}$, $10^{-3} / \mathrm{s}$; (g) $920^{\circ} \mathrm{C}, 10^{-4} / \mathrm{s}$; (h) $950^{\circ} \mathrm{C}, 10^{-2} / \mathrm{s}$; (i) $950^{\circ} \mathrm{C}, 10^{-3} / \mathrm{s}$; (j) $950{ }^{\circ} \mathrm{C}, 10^{-4} / \mathrm{s}$.

\subsection{Grain Rearrangement}

Significant grain rearrangement occurs during deformation. As the deformation begins, the adjacent grains are separated from each other, as shown in Figure 8 by optical microscopy at $920^{\circ} \mathrm{C}$ and $10^{-3} / \mathrm{s}$. The interstices between grains are smaller than the grain sizes but have the same magnitude order as the grain sizes. A strip-shaped gap is formed between grain $A$ and $C$, and similar observations can be obtained between grains $A-B$, B-E, and C-D. Such gaps meet and fuse to form voids and cavitation, which is part of the mechanism for the titanium alloy.

Intergranular clearance and grain boundary slip together lead to grain rearrangement of the Ti-6Al-4V alloy, and grain rearrangement becomes easier during grain rotation [32]. The relative movements between adjacent grains depend on the orientations of their common boundaries [33], and the grains with small angles to the tensile axis move more slowly than those with other orientations. The rotation of grains is also caused by the difference in relative motion velocity between grains [34], so the rotation of grains is, to some extent, the result of grain rearrangement. 


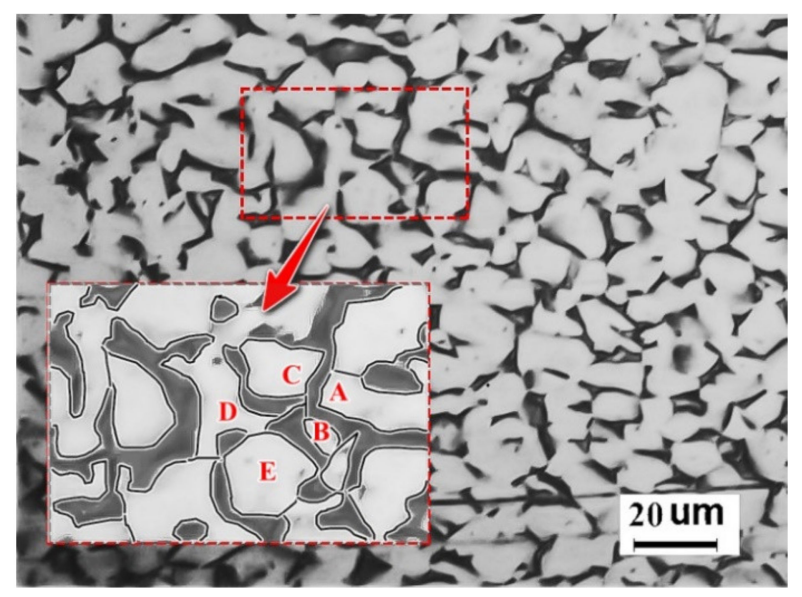

Figure 8. Optical microscopy of sample at $920^{\circ} \mathrm{C}$ and strain rates of $10^{-3} / \mathrm{s}$.

\subsection{Deformation Mechanism}

A superplastic deformation mechanism schematic diagram of the Ti-6Al-4V alloy was drafted by comprehensively considering the above discussion on rheological behavior and microstructure evolution, as shown in Figure 9. Grain boundary sliding is the dominant deformation mechanism for the titanium alloy, and grain rotation is the accommodation mechanism, now named the Grain rotation accommodated GBS mechanism.
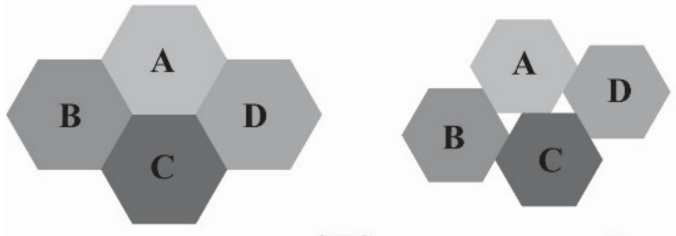

(a) GBS (b) Rearrangment
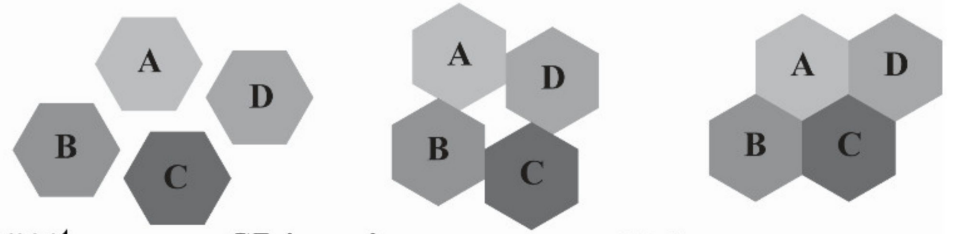

(c) GR in grains<smiles>[GeH3]</smiles>
GBS (e)


(f) $\stackrel{\text { Dislocations to LABs }}{\longrightarrow}$ (g) LABs to HABs
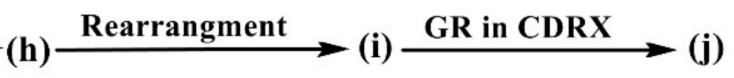

Figure 9. Schematic diagram of GR accommodated the GBS mechanism.

During deformation, the grains always maintain equiaxial grains, and the deformation is mainly accomplished by grain boundary sliding. Grain rearrangement occurs when GBS is blocked by other grains. During grain rearrangement, grain rotation occurs due to heterogeneous GBS velocity distribution. Then, the grains continue to slide at grain boundaries, and the superplastic formation continues.

CDRX for the Ti-6Al-4V alloy during superplastic deformation is illustrated in Figure $9 \mathrm{f}-\mathrm{j}$. The dislocation multiplications at the steps of grain boundaries and dislocations move within the grain until they meet the grain boundaries or subgrain boundaries. Then, the dislocations accumulate and form new subgrain boundaries. With the deformation, LABs transfer to HABs, then the recrystallized grains slide after grain rearrangement and grain rotation with grain growth. 


\section{Conclusions}

The flow behavior and microstructure evolution of the Ti-6Al-4V alloy during superplastic deformation was investigated. Temperatures ranged from $890-950{ }^{\circ} \mathrm{C}$, and the selected strain rates were $10^{-2}, 10^{-3}$, and $10^{-4} / \mathrm{s}$. A grain boundary sliding accommodated mechanism considering the grain rotation and continuous dynamic recrystallization is proposed. This work is the basis for subsequent research into mathematical multiscale modeling and process studies.

Author Contributions: J.Y.: investigation, methodology, experiment, writing; J.W.: methodology, reviewing. All authors have read and agreed to the published version of the manuscript.

Funding: Key Research and Development Program of Shaanxi, Program No. 2020ZDLGY01-05.

Data Availability Statement: Not applicable.

Acknowledgments: The support of the Key Research and Development Program of Shaanxi, Program No. 2020ZDLGY01-05, is acknowledged.

Conflicts of Interest: We declare that we have no financial and personal relationships with other people or organizations that can inappropriately influence our work, there is no professional or other personal interest of any nature or kind in any product, service and/or company that could be construed as influencing the position presented in, or the review of, the manuscript entitled, "The grain rotation accommodated the GBS mechanism for Ti-6Al-4V alloy during the superplastic deformation".

\section{References}

1. Kopec, M.; Wang, K.; Politis, D.J.; Wang, Y.; Wang, L.; Lin, J. Formability and microstructure evolution mecha-nisms of Ti6Al4V alloy during a novel hot stamping process. Mater. Sci. Eng. A 2018, 719, 72-81. [CrossRef]

2. Liu, J.; Khan, A.S.; Takacs, L.; Meredith, C.S. Mechanical behavior of ultrafine-grained/nanocrystalline titanium synthesized by mechanical milling plus consolidation: Experiments, modeling and simulation. Int. J. Plast. 2015, 64, 151-163. [CrossRef]

3. Ratochka, I.; Lykova, O.; Mishin, I.; Naydenkin, E. Superplastic deformation behavior of Ti-4Al-2V alloy gov-erned by its structure and precipitation phase evolution. Mater. Sci. Eng. A 2018, 731, 577-582. [CrossRef]

4. Zhang, W.; Ding, H.; Cai, M.; Yang, W.; Li, J. Low-temperature superplastic deformation mechanism in Ti-6Al-4V alloy processed by friction stir processing. Mater. Sci. Eng. A 2019, 764, 138261. [CrossRef]

5. Alabort, E.; Putman, D.; Reed, R.C. Superplasticity in Ti-6Al-4V: Characterisation, modelling and applications. Acta Mater. 2015, 95, 428-442. [CrossRef]

6. Cao, W.; Huang, C.; Wang, C.; Dong, H.; Weng, Y. Dynamic reverse phase transformation induced high-strain-rate superplasticity in low carbon low alloy steels with commercial potential. Sci. Rep. 2017, 7, 1-6. [CrossRef] [PubMed]

7. Moshtaghioun, M.B.; Bejarano-Palma, J.A.; García, D.G. Disclination dipoles are the Holy Grail for high temper-ature superplasticity in ceramics. Scr. Mater. 2020, 185, 21-24. [CrossRef]

8. Yin, S.; Zhang, Z.; Yu, J.; Zhao, Z.; Liu, M.; Bao, L.; Jia, Z.; Cui, J.; Wang, P. Achieving excellent superplasticity of Mg-7Zn-5Gd-0.6Zr alloy at low temperature regime. Sci. Rep. 2019, 9, 1-14. [CrossRef]

9. Alabort, E.; Barba, D.; Shagiev, M.; Murzinova, M.; Galeyev, R.; Valiakhmetov, O.; Aletdinov, A.; Reed, R. Alloys-by-design: Application to titanium alloys for optimal superplasticity. Acta Mater. 2019, 178, 275-287. [CrossRef]

10. Lu, Y.; Aristizabal, M.; Wang, X.; Pang, B.; Chiu, Y.; Kloenne, Z.; Fraser, H.; Loretto, M. The influence of heat treatment on the microstructure and properties of HIPped Ti-6Al-4V. Acta Mater. 2019, 165, 520-527. [CrossRef]

11. Yang, J.; Wu, J.; Zhang, Q.; Han, R.; Wang, K. Investigation of flow behavior and microstructure of Ti-6Al-4V with annealing treatment during superplastic forming. Mater. Sci. Eng. A 2020, 797, 140046. [CrossRef]

12. Palumbo, G.; Guglielmi, P.; Piccininni, A.; Ferrer, I.; Garcia-Romeu, M.L. Manufacturing of a hemispherical com-ponent combining incremental forming and superplastic forming. CIRP J. Manuf. Sci. Technol. 2020, 30, 178-188. [CrossRef]

13. Zhang, W.; Gao, Y.; Feng, Z.; Wang, X.; Zhang, S.; Huang, L.; Huang, Z.; Jiang, L. Ductility limit diagrams for su-perplasticity and forging of high temperature polycrystalline materials. Acta Mater. 2020, 194, 378-386. [CrossRef]

14. Despax, L.; Vidal, V.; Delagnes, D.; Dehmas, M.; Matsumoto, H.; Velay, V. Influence of strain rate and tempera-ture on the deformation mechanisms of a fine-grained Ti-6Al-4V alloy. Mater. Sci. Eng. A 2020, 790, 139718. [CrossRef]

15. Langdon, T.G. The mechanical properties of superplastic materials. Met. Mater. Trans. A 1982, 13, 689-701. [CrossRef]

16. Alabort, E.; Kontis, P.; Barba, D.; Dragnevski, K.; Reed, R.C. On the mechanisms of superplasticity in Ti-6Al-4V. Acta Mater. 2016, 105, 449-463. [CrossRef]

17. Mandal, P.; Gomez-Gallegos, A.; Gonzalez, D.; Elrakayby, H.; Blackwell, P. Superplastic Behaviour of Ti54M and Ti64. In Proceedings of the 14th World Conference on Titanium, Nantes, France, 10-14 June 2019. 
18. Mosleh, A.O.; Kotov, A.D.; Vidal, V.; Mochugovskiy, A.G.; Velay, V.; Mikhaylovskaya, A.V. Initial microstructure influence on Ti-Al-Mo-V alloy's superplastic deformation behavior and deformation mechanisms. Mater. Sci. Eng. A 2020, $802,140626$. [CrossRef]

19. Mosleh, A.O.; Mikhaylovskaya, A.V.; Kotov, A.D.; Sitkina, M.; Mestre-Rinn, P.; Kwame, J.S. Superplasticity of Ti-6Al-4V Titanium Alloy: Microstructure Evolution and Constitutive Modelling. Materials 2019, 12, 1756. [CrossRef]

20. Wang, K.; Shi, C.; Zhu, S.; Wang, Y.; Shi, J.; Liu, G. Hot Gas Pressure Forming of Ti-55 High Temperature Titanium Alloy Tubular Component. Materials 2020, 13, 4636. [CrossRef]

21. Wu, Y.; Fan, R.; Chen, M.; Wang, K.; Zhao, J.; Xiao, W. High-temperature anisotropic behaviors and microstructure evolution mechanisms of a near- $\alpha$ Ti-alloy sheet. Mater. Sci. Eng. A 2021, 820, 141560. [CrossRef]

22. Ashby, M.; Verrall, R. Diffusion-accommodated flow and superplasticity. Acta Met. 1973, 21, 149-163. [CrossRef]

23. Spingarn, J.; Nix, W. Diffusional creep and diffusionally accommodated grain rearrangement. Acta Met. 1978, 26, 1389-1398. [CrossRef]

24. Naziri, H.; Pearce, R.; Brown, M.H.; Hale, K.F. In situ superplasticity experiments in the 1 million volt electron microscope. J. Microsc. 1973, 97, 229-238. [CrossRef]

25. Ball, A.; Hutchison, M.M. Superplasticity in the Aluminum-Zinc Eutectoid. Met. Sci. 1969, 3, 1-7. [CrossRef]

26. Weinstein, A.M.; Ferraglio, P.; Mukherjee, K. Dynamic strain aging of carbon doped Ni. Mater. Sci. Eng. 1971, 8, 198-202. [CrossRef]

27. Paidar, V. Geometry of asymmetrical grain boundaries. Philos. Mag. A 1992, 66, 41-54. [CrossRef]

28. Velay, V.; Matsumoto, H.; Vidal, V.; Chiba, A. Behavior modeling and microstructural evolutions of Ti-6Al-4V alloy under hot forming conditions. Int. J. Mech. Sci. 2016, 108-109, 1-13. [CrossRef]

29. Kang, S.-H.; Choi, S.-W.; Im, Y.-D.; Lee, Y.-K. Grain boundary sliding during high-temperature tensile deformation in superplastic Fe-6.6Mn-2.3Al steel. Mater. Sci. Eng. A 2020, 780, 139174. [CrossRef]

30. Luo, J.; Li, M.; Li, X.; Shi, Y. Constitutive model for high temperature deformation of titanium alloys using internal state variables. Mech. Mater. 2010, 42, 157-165. [CrossRef]

31. Borodin, E.; Mayer, A.; Gutkin, M. Coupled model for grain rotation, dislocation plasticity and grain boundary sliding in fine-grained solids. Int. J. Plast. 2020, 134, 102776. [CrossRef]

32. Beere, W. Grain-boundary sliding controlled creep: Its relevance to grain rolling and superplasticity. J. Mater. Sci. 1977, 12, 2093-2098. [CrossRef]

33. Geckinli, A.E.; Barrett, C.R. Superplastic deformation of the Pb-Sn eutectic. J. Mater. Sci. 1976, 11, 510-521. [CrossRef]

34. Matsuki, K.; Morita, H.; Yamada, M.; Murakami, Y. Relative motion of grains during superplastic flow in an Al-9Zn-1 wt.\%Mg alloy. Met. Sci. 1977, 11, 156-163. [CrossRef] 